\title{
Monitoring fine and ultrafine particles in the atmosphere of a Southeast Chinese city
}

\author{
Le Jian,* ${ }^{a}$ Yi-Ping Zhu' ${ }^{b}$ and Yun Zhao ${ }^{a}$ \\ Received (in $X X X, X X X) X$ th $X X X X X X X X X 200 X$, Accepted $X$ th $X X X X X X X X X 200 X$ \\ ${ }_{5}$ First published on the web $X$ th $X X X X X X X X X 200 X$ \\ DOI: 10.1039/b000000x
}

There have been few studies on submicron particles in the atmosphere reported from developing countries. With rapid economic development, the size of the road vehicle fleet has increased dramatically in China. The increase in vehicle emissions has raised concerns about air quality, especially in the urban areas of this developing country. A model study was conducted in Hangzhou, a city in ${ }_{10}$ Southeast China with the aim of characterizing the emission patterns of submicron particles $\leq 1.0$ micron from on-road vehicles and the impact of vehicle density and speed on the concentrations of submicron particles in the atmosphere. Results showed that the average ultrafine particle (UFP) number concentration was 45805 particles $\mathrm{cm}^{-3}$ and the average mass concentration of particulate matter 1.0 (PM1.0) was 217 $\mathrm{g} \mathrm{m} \mathrm{m}^{-3}$ during the survey period. Autoregressive Integrated Moving Average modelling results indicated that an increase of vehicle density and driving speed were positively correlated with the increase of UFP and PM1.0 concentrations $(P<0.05)$ in the

15 atmosphere. Results from this study suggest that vehicle density and driving speed are significant predictors of submicron particles emissions. This study provides first hand information for future investigations on the submicron particle emissions in Hangzhou, a city with rapidly increasing vehicle numbers and for further investigations into a possible causal relationship between submicron particles and health effects on local residents.

\section{${ }_{20}$ 1. Introduction}

Along with the rapid increase in its gross domestic product (GDP, number two in the world in 2009), the size of the on-road vehicle fleet in China has increased dramatically. By the end of 2008, the total number of vehicles in China was 64.7 million. ${ }^{1}$ This is an

25 increase of $13.5 \%$ from a year before ( 57.0 million) and is double the number just 5 years ago. The continued growth of the vehicle fleet is an area of growing concern because of its impact on air quality. The National Bureau of Statistics of China reported that in 2008 there were 113 cities (21.8\% of total 519 cities monitored) 30 having an air quality "unhealthy for sensitive groups" (Air Pollution Index value between 101 and 150, Grade III ). ${ }^{1}$

Particulate matter (PM) is defined by the U.S. Environmental Protection Agency as "very small pieces of solid or liquid matter, such as particles of soot, dust, fumes, mists, or aerosols". ${ }^{2}$ Before 35 2000, the total suspended particle (TSP, $\leq 100 \mu \mathrm{m}$ aerodynamic diameter), an older regulatory measure of the mass concentration of PM in air, was the main indicator for monitoring ambient air quality in China. With the release of the revised National Ambient Air Quality Standards in 1996 (GB3095-96), an 40 improved indicator of particles that can enter the thorax and lower respiratory tract, PM10 $(\leqslant 10 \mu \mathrm{m})$, was introduced in the assessment of ambient air quality in China.

\footnotetext{
${ }^{a}$ School of Public Health, Curtin Health Innovation Research Institute, Curtin University, Perth, Australia. Fax: +61 89266 2958; Tel: +61 8 9266 4250; Email: l.jian@curtin.edu.au

${ }^{b}$ Hangzhou Traffic Administration and Control Centre, Hangzhou, P.R. China
}

Particulate matter equal to or less than $2.5 \mu \mathrm{m}$ is referred to as fine particles or PM2.5 and is not currently regulated in China. However a number of studies in the last decade have quantified and characterized PM2.5 levels in China. ${ }^{3-7}$

50 Ultrafine particles (UFPs) are particles with an aerodynamic diameter of $0.1 \mu \mathrm{m}$ (100nm or PM0.1) or less and sometimes are referred to as nanoparticles (a particle with at least one dimension less than 100nm). Because UFPs contain a large variety of chemical compounds and have a relatively short atmospheric half ${ }_{55}$ life, they have not been well studied and there are gaps in our understanding of their sources, physicochemical characteristics, atmospheric behaviours and health effects. ${ }^{8}$ There is far less research on ambient air UFPs and PM1.0 worldwide compared with PM10 and PM2.5. ${ }^{9-23}$ Research by Morawska et al. ${ }^{24}$ 60 indicated that existing ambient air quality standards (in Australia) are restricted to PM2.5 and PM10 fractions generated by mechanical processes and they are unable to effectively control submicron particles emitted from combustion sources such as motor vehicles. However, currently there are insufficient data for ${ }_{65}$ establishing standards for atmospheric submicron particles such as UFPs (nanoparticles) and PM1.0 worldwide. Lee et al. also concluded from their study ${ }^{25}$ that PM1.0 is a better indicator for vehicular emissions than PM2.5. In addition, there are few published research reports on the impact of on-road vehicle ${ }_{70}$ density and driving speed on atmospheric submicron particle concentrations.

Recent studies have shown that UFPs can penetrate deeper into the airways of the respiratory tract and cause adverse health effects to the respiratory system and other systems. ${ }^{21,26-32}$ In order 75 to investigate the patterns and concentrations of UFPs and PM1.0 emitted from on-road vehicles and the influence of vehicle density and speed on the emissions of submicron particles, a model study was conducted in Hangzhou, a city in Southeast China in 2009. The study will also provide baseline data for 
future investigation of health effects and regulation of ambient air UFPs and PM1.0.

\section{Data and methods}

\section{${ }_{5}$ 2.1. Vehicle data sources}

Information on real time vehicle flow and driving speed on the road was collected by using a real time traffic surveillance system which is able to count the vehicle numbers and record driving speed when vehicles pass through the surveillance point. This 10 traffic information database is maintained by the City Traffic Control and Administration Centre. Information on numbers of newly registered automobiles in this city in 2000, 2004 and 2008 was obtained from the database of the City Vehicle Licensing Centre.

15

\subsection{Monitoring venue}

The ambient air monitoring survey was conducted on Zhong He Viaduct at the city centre (see Figure 1) in February 2009. Zhong He Viaduct is a two-way vehicle-only viaduct, with two lanes in 20 each direction. The length of the viaduct is about $20 \mathrm{~km}$ from north to south with 10 exits on each side. The sampling venue was near Huan Cheng North Road in the middle of the viaduct and one meter away from the edge of the road and outside a sentry box (the star in Fig. 1).

25

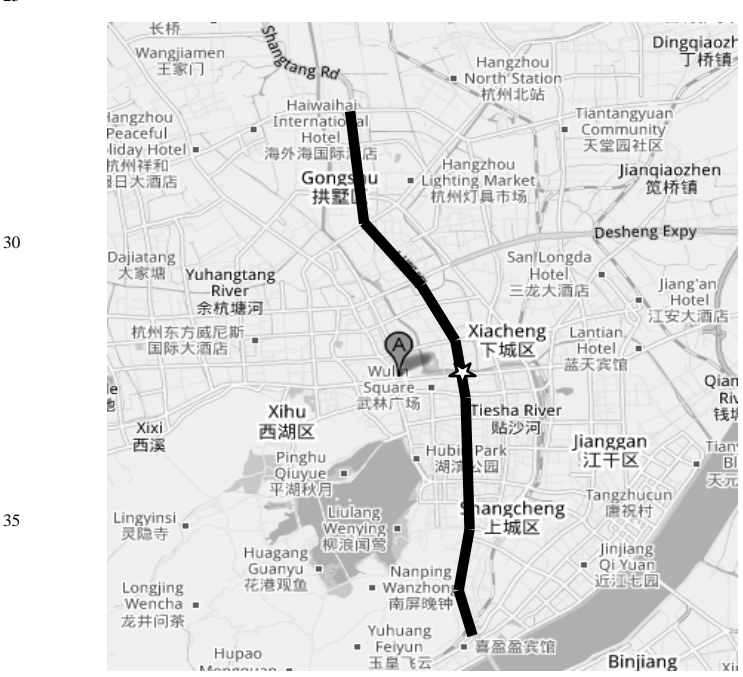

Fig. 1 Map of the City Centre. The solid black line represents Zhong He 40 Viaduct. 5 Sampling venue

\subsection{Sampling methods}

The condensation particle counter (CPC) is the most frequently used technique to measure particle number concentration, in ${ }_{45}$ particular, for UFPs. ${ }^{32}$ The P-Trak Ultrafine Particle Counter (Model 8525, TSI, USA) is a portable CPC instrument measuring particles from $0.02 \mu \mathrm{m}$ to $1 \mu \mathrm{m}$. It reflects time-weighted average particle number concentrations (particles $\mathrm{cm}^{-3}$ ) up to 500000 particles $\mathrm{cm}^{-3}$. The P-Trak counts ultrafine particles by sending 50 them through a supersaturated atmosphere and causing isopropyl alcohol to condense on them. This results in particles growing to a size that can be detected and counted. ${ }^{33}$ As its sensitivity, convenience, cost-effectiveness and the measurement well represents the general trend of UFP, several research projects 55 conducted in Canada, USA, Sweden and UK have used the P-

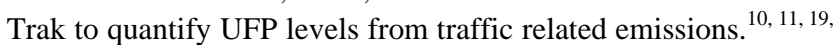
${ }^{34,} 35$ In this study, a P-Trak Ultrafine Particle Counter was used to measure total UFP counts. The instrument was calibrated by the manufacturer. According to the manufacturer, 3772 CPCs were 60 used as the reference equipment $(0.01-3 \mu \mathrm{m})$ and the calibration system meets the International Organization for Standardization (ISO) 9001:2008 and complies with ISO 10012:2003, Quality Assurance Requirements for Measuring Equipment. The P-Trak was zero calibrated prior to sampling each day and the isopropyl 65 alcohol cartridge was replaced every 5.5 hours. TrakPro (Version 3.6.2) software was used to program the instrument for measuring UFP 11 hours a day from 7:30 to 18:30 at one minute sampling interval for a period of seven days. The equipment was located on a one-metre high solid bench with the tip of the sampling wand 70 fixed at one meter away from the traffic lanes.

TSI real time DustTrak ${ }^{\mathrm{TM}}$ Aerosol Monitor 8520 is a portable laser-scattering photometer. It contains a laser diode directed at a continuous aerosol stream and measures real time particle mass concentration for particles sizes from $0.1 \mu \mathrm{m}$ to $1.0 \mu \mathrm{m}$ 75 (PM0.1 1.0). Comparison studies by Wallace et al. ${ }^{36}$ between DustTraks and Kingham et al. ${ }^{37}$ between DustTrak and tapered element oscillating microbalance (TEOM) did show good agreements (coefficient of determination $\left(R^{2}\right)=0.90$ and 0.98 ) between measurements. In this study, the PM1.0 was measured 80 by the DustTrak 8520. The DustTrak was calibrated by the manufacturer to the respirable fraction of the ISO 12103-1, A1 Arizona road dust. The particle sizes of Arizona test dust cover from $0.1 \mu \mathrm{m}$ to $10 \mu \mathrm{m}$ and it is commonly used for calibration because of its representativeness for a wide variety of ambient 85 aerosols. $^{38}$ The DustTrak was zero checked using a HEPA filter prior to sampling each day. It was placed beside the P-Trak with a $1.0 \mu \mathrm{m}$ impactor attached to the inlet nozzle. The inlet nozzle was faced to the road and was parallel to the P-Trak wand. The flow rate of the device was set at $1.7 \mathrm{~L} \mathrm{~min}{ }^{-1}$ and the log interval 90 was set at $1 \mathrm{~min}$.

Quality assurance measurements also included flow checks, time and logging data synchronising. Side by side comparison measurement between portable CPCs (8525 vs. 3007) and DustTraks (8520 vs. 8520) in a laboratory and on a busy road 95 were conducted. TSI 3007 is a new generation of P-Trak. Both 8525 and 3007 work with the same principle except that 3007 can measure particle size down to $0.01 \mu \mathrm{m}$ and that of 8525 is 0.02 $\mu \mathrm{m}$. Results showed that measurements between portable DustTraks (PM1.0 mass concentration) and CPCs (UFP number 100 concentration) achieved relative good agreement with Pearson correlation coefficient $(R)$ ranges from 0.903 to 0.968 and $R^{2}$ ranges from 0.815 to 0.936 for both instruments. The comparison results were similar as those obtained in Matson et al. study. ${ }^{39}$ That means that the monitoring instruments used in this study 105 enable comparison of results to both PM1.0 mass concentrations and UFP number concentrations.

In addition to the collection of submicron particulate data, atmospheric temperature and relative humidity during the survey 
period were recorded by a HDL TINYTAG Ultra 2 Data logger. Data on barometric pressure, wind velocity, wind direction and rainfall were also collected from the Hangzhou Meteorological Data Service Centre. Although a large volume of information was 5 collected, this paper will focus only on the atmospheric concentrations of UFPs and PM1.0 and the influence of vehicle density and speed on the emissions of the submicron particles. The submicron particle emissions and their relationship with meteorological factors will be reported separately.

10

\subsection{Statistical analysis}

All data analyses were carried out using the Statistical Package for Social Science, Advanced statistics, Release 17.0 (SPSS Inc., Chicago, IL, USA). As both UFP and PM1.0 concentrations were 15 not normally distributed, median was used to describe the average concentrations and range was used to describe the range between the minimum and the maximum concentration obtained during the monitoring period.

Because UFP and PM1.0 concentrations are measured 20 successively at equally spaced time intervals (each day and each minute) and possess nature characteristics of time series data, the observations of UFP and PM1.0 concentrations are thus probably be dependent (auto-correlated). ${ }^{40}$ It is no doubt that one of the key assumptions of standard linear regression, such as independence 25 of successive observations, is violated, implying that the standard linear regression method fails to account for the inherent variability or correlation structure in the two concentrations across the time.

The methodology of Autoregressive Integrated Moving 30 Average (ARIMA) model, an integration of the AR (Autoregressive) and MA (Moving Average) models, is considered to have the best performance for minimising the residual variance for the time series data. The ARIMA modelling also has a reputation of providing a better understanding to this 35 type of data and a reliable forecasting of future values in the series. ${ }^{41,42}$ In order to determine the effects of vehicle density and driving speed on UFP and PM1.0 concentrations, an ARIMA analysis was applied to model the UFP and PM1.0 time series data. The modelling was carried out using the SPSS ARIMA 40 procedure which implements Melard's maximum likelihood estimation algorithm with an assumption of no missing values. Mathematically the SPSS ARIMA (p, d, q) model can be written as:

$$
\varphi_{p}(B)\left[\Delta\left(Y_{t}-\sum_{i=1}^{K} c_{i} X_{i t}\right)-\mu\right]=\theta_{q}(B) a_{t}
$$

45 where $B$ is the backshift operator $B Y_{t}=Y_{t-1}$, $\Delta=(1-B)^{d}$ is the differencing operator, $\varphi_{p}(B)=1-\varphi_{1} B-\varphi_{2} B^{2}-\varphi_{3} B^{3}-\cdots-\varphi_{p} B^{p} \quad$ is $\quad$ the autocorrelation (AR) polynomial,

$\theta_{q}(B)=1-\theta_{1} B-\theta_{2} B^{2}-\theta_{3} B^{3}-\cdots-\theta_{q} B^{q} \quad$ is the

50 moving average (MA) polynomial, $X_{i t}, i=1,2, \cdots K$ are predictors of the dependent variable $Y_{t}, t=1,2, \cdots, N$, and $a_{t}$ is the random noise normally distributed with mean zero and variance $\sigma_{a}^{2}$. The estimated coefficient $\hat{C}_{i}$ of the $i^{\text {th }}$ predictor is the adjusted effect of the predictor on the dependent variable $Y_{t}$, 55 after controlling for autocorrelation and moving average effects specified (if any) in the ARIMA model.

For a reliable ARIMA modelling, at least 50 observations are recommended ${ }^{40}$ and the number is 144 in this analysis. In the ARIMA model, both explanatory variables were recorded as 60 categorical variables. Traffic flow was categorised into low $(<645$ per 10 mins), moderate (645 730 per 10 mins) and heavy ( $>730$ per 10 mins) and driving speed was classified into slow ( $<80 \mathrm{~km}$ $\left.\mathrm{h}^{-1}\right)$, medium $\left(80 \sim 87 \mathrm{~km} \mathrm{~h}^{-1}\right)$ and high $\left(>87 \mathrm{~km} \mathrm{~h}^{-1}\right)$ based on the tertiles of the variables' distributions. A $P$ value less than 0.05 is 65 considered as statistically significant.

\section{Results and discussion}

\subsection{Growing new vehicle numbers in Hangzhou}

Hangzhou is the capital city of Zhejiang Province with a total 70 population of 4.2 million in the metropolitan area at the end of $2008{ }^{43}$ The total number of newly registered on-road cars, buses and trucks in Hangzhou in 2008 was 3.6 times greater than the numbers in 2000. Among them, the number of gasoline fueled vehicles increased 4.4 times and diesel fueled vehicles increased 751.2 times. Details can be found in Table 1. Increases in newly registered cars, buses and trucks have raised concerns over air quality in the urban area of this capital city, especially the emission of fine and ultrafine particles from vehicles.

80 Table 1 Comparison of newly registered vehicle numbers ${ }^{\mathbf{a}}$ between year 2000, 2004 and 2008

\begin{tabular}{lccc}
\hline Year & Gasoline vehicles & Diesel vehicles & Total \\
\hline 2000 & 21208 & 7679 & 28887 \\
2004 & 86477 & 15051 & 101528 \\
2008 & 115383 & 16776 & 132159 \\
\hline
\end{tabular}

a Only include on-road service cars, buses and trucks.

\subsection{Concentrations of PM1.0, UFP and traffic flow}

85 Table 2 shows average UFP and PM1.0 concentrations as well as the traffic flow at Zhong He Viaduct during the monitoring period. The average concentration of PM1.0 was $217 \mu \mathrm{g} \mathrm{m}^{-3}$ (30 $506 \mu \mathrm{g} \mathrm{m}^{-3}$ ) and average UFP concentration was 45805 particles $\mathrm{cm}^{-3}$ (10 $428-147350$ particles $\mathrm{cm}^{-3}$ ), respectively. Total traffic 90 flow during the 7:30 to $18: 30$ period was 43588 vehicles that was about 3974 vehicles per hour and 63968 vehicles a day (24h). Diesel vehicles on this road were about 2 3\%. That means there were about 1600 diesel vehicles a day driving through on the Viaduct.

95 Along with particulates measurement, the average atmosphere temperature ranged from $8.2^{\circ} \mathrm{C}$ to $21.6^{\circ} \mathrm{C}$ and average wind speed ranged from $1.7 \mathrm{~m}^{-\mathrm{s}}$ to $3.8 \mathrm{~m}^{-\mathrm{s}}$. As the dominant wind direction during the monitoring period was northwest, heading in parallel with the axis of the road, the impact of wind direction on 100 the concentrations of monitored submicron particles was considered as negligible in this study. 
Table 2 Concentrations of submicron particles and traffic flow on Zhong He Viaduct during the monitoring period

\begin{tabular}{|c|c|c|c|c|}
\hline Date & $\begin{array}{l}\text { PM1.0 } \mu \mathrm{g} \mathrm{m}^{-3} \\
\text { Median (range) }\end{array}$ & $\begin{array}{l}\text { UFP Particle } \mathrm{cm}^{-3} \\
\text { Median (range) }\end{array}$ & $\begin{array}{c}\text { Total vehicle } \\
\text { numbers }\end{array}$ & $\begin{array}{c}\text { Average vehicle } \\
\text { numbers } \mathrm{h}^{-1}\end{array}$ \\
\hline Monday, 9 & $202(135$ - 369) & 45679 (1 7245 122 230) & 40853 & 3714 \\
\hline Tuesday, 10 & $275(192-372)$ & -- & 44703 & 4064 \\
\hline Wednesday, 11 & $277(250-328)$ & 30963 (2 3971 38 003) & 43108 & 3919 \\
\hline Thursday, 12 & $177(96-602)$ & -- & 43456 & 3951 \\
\hline Friday, 13 & $272(152-506)$ & 25277 (1 0428 120 928) & 48586 & 4417 \\
\hline Thursday, 19 & $105(30-246)$ & 49475 (1 $7941 \sim 147350)$ & 38918 & 3538 \\
\hline Sunday, 22 & $253(137-458)$ & 58624 (1 $7461 \sim 116483)$ & 45490 & 4215 \\
\hline
\end{tabular}

The vehicle density on the viaduct was high in the daytime from 7:30 to 18:30 and low from 23:00 to 7:00 the next day. The 5 morning peak was usually at 8:00 and afternoon peak was at 17:30. The traffic flow patterns were similar throughout the survey period (see Fig. 2).

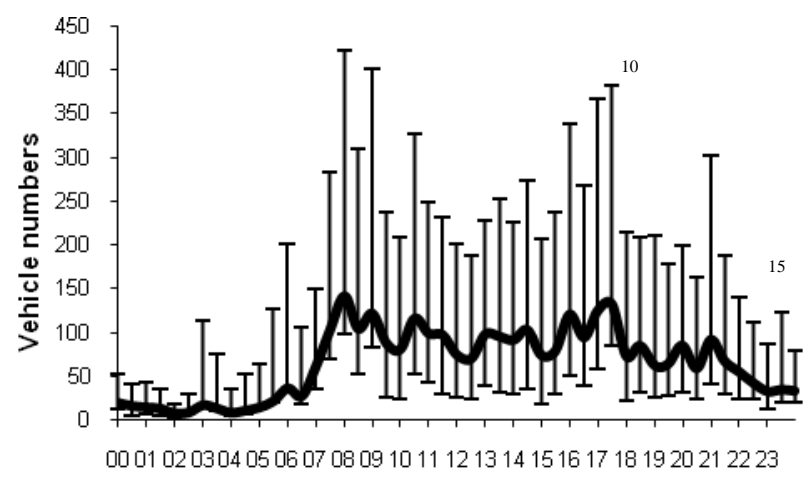

Time (hour)

Fig. 2 The traffic flow pattern observed during the monitoring period (Feberary, 2009).

Compared to the total mass of PM emitted from an engine, the mass of submicron particles is relatively small. The number concentration of UFP is responsible for the majority of the total particle number concentration from vehicles and is dominated by 25 the nuclei and accumulation modes, which typically consists of particles in the size range 20-30nm from diesel engines and 20$60 \mathrm{~nm}$ from petrol engines. ${ }^{44-46}$ Charron and Harrison reported from their study that the accumulation mode particles are associated with emissions from heavy-duty traffic while particles 30 in the range of 30-60nm are associated with light-duty vehicles. ${ }^{15}$

Compared with research on atmospheric PM10 and PM2.5, research on UFP emissions on busy roads is understudied. Using mobile sampling methods and CPCs, several studies conducted in European countries and North America have measured UFP 35 emissions from vehicles on busy traffic road. By driving a mobile platform around the Los Angeles roadway network, Westerdahl et al. found that average particle number concentrations of UFP (0.01 to $1 \mu \mathrm{m})$ ranged from 33000 to 190000 particle $\mathrm{cm}^{-3}$ and the UFP concentration was correlated to truck traffic density (47 40000 particle $\mathrm{cm}^{-3}$ on $110 \mathrm{~N}$ freeway with $\sim 3500$ trucks per day and 190000 particle $\mathrm{cm}^{-3}$ on the 710S Freeway with 25000 truck per day). ${ }^{9}$ Kaur and Nieuwenhuijsen reported a field campaign conducted in Central London $^{11}$ via five modes of transport (walking, cycling, bus, car and taxi). Measured by TSI
${ }_{45}$ P-Trak Ultrafine Particle Counters, the UFP concentration was around 59 798-100 629 particles $\mathrm{cm}^{-3}$. Another similar campaign conducted in Montreal, Canada investigated UFP levels in three different modes of transport (walking, on a bus and in an automobile along a highway). ${ }^{10}$ They reported that average UFP 50 counts around 38348 particles $\mathrm{cm}^{-3}$ for a bus road travel with about 2000 vehicles per hour. In the Helsinki study, Pirjola, et al 47 used a mobile laboratory at $40 \mathrm{~km} \mathrm{~h}^{-1}$ on a highway and measured UFP levels by an electrical low pressure impactor (ELPI) with a size range of $0.007-10 \mu \mathrm{m}$ and the Hauke-type 55 scanning mobility particle sizers (SMPS) with a CPC3025 (size 3 - $50 \mathrm{~nm}$ ). They reported that approximately $90 \%$ of the total particle number concentrations were particles smaller than $50 \mathrm{~nm}$. The traffic was busy towards 2290 vehicles per hour in the morning and the peak concentrations often exceeded 200000 60 particles $\mathrm{cm}^{-3}$ and sometime reached a value of $10^{6} \mathrm{~cm}^{-3}$. Another similar study ${ }^{48}$ on an interstate highway from Rochester to Buffalo reported average daily total particle number concentrations $(0.003-1 \mu \mathrm{m})$ ranged from 200000 to 560000 particles $\mathrm{cm}^{-3}$. In addition, several studies have measured particle 65 number concentrations at the roadside or near roadside such as the study conducted by Beckerman et al. ${ }^{34}$ They measured UFP number concentrations by P-Trak and GRIMMM CPC (0.01 $2.5 \mu \mathrm{m})$ near the Highway 401 in Toronto. The average P-Trak result was 33867 (4153 - 95 549) particles $\mathrm{cm}^{-3}$ for a period of 70 11.3h. Hagler et al. $^{19}$ used P-Trak and measured UFP at a distance of $20 \mathrm{~m}$ from a busy road in Raleigh with average vehicle numbers of 5208 per hour and 2-5\% of heavy duty vehicles. The peak number concentration on the downwind side reached 60000 particles $\mathrm{cm}^{-3}$ during the weekday rush hour. Another study 75 conducted in Corpus Christi in USA $^{13}$ reported similar levels of UFP number concentrations near busy roads. Yue et al. ${ }^{49}$ used TSI SMPS 3080 with a CPC3025A and an Aerodynamic Particle Sizer 3321 and monitored UFPs in a south Chinese city, Guangzhou. The reported average urban background particle 80 number concentration in Guangzhou was $29000 \pm 11000$ particles $\mathrm{cm}^{-3}$.

Apart from UFP (PM0.1), research on traffic related PM1.0 emission is even rarer. PM1.0 is commonly measured by filter or gravimetric based methods or light scattering approaches. Using 85 optical particle counter GRIMM Perez et al. ${ }^{50}$ observed the average mass concentration of PM1.0 to be $17\left(3-73 \mu \mathrm{g} \mathrm{m}^{-3}\right)$ on the terrace of a two storey building at $150 \mathrm{~m}$ from a main street in Barcelona. In another coastal city in Spain, Rodriguez et al. ${ }^{51}$ observed $9 \mu \mathrm{g} \mathrm{m}^{-3}$ of PM1.0 at the urban background by using the 
GRIMM. Ariola et al. ${ }^{52}$ reported concentrations of PM1.0 from 16 to $23 \mu \mathrm{g} \mathrm{m}^{-3}$ in the urban area of a coastal town in Northwest Italy by using the TEOM. There are three recent studies conducted in China that measured urban background or roadside 5 PM1.0 fraction. Lee, et al. ${ }^{25}$ conducted a roadside air monitoring project in Hong Kong in 2004 with a Partisol-Plus Model 2025 Sequential Air Sampler and weighted particles collected on quartz filters. The average reported PM1.0 was $35.9 \pm 12.4 \mu \mathrm{g} \mathrm{m}^{-3}$ with the highest concentration on the day of $14 \mathrm{Feb}$ at $85.0 \mu \mathrm{g} \mathrm{m}^{-3}$.

10 Lin and Lee ${ }^{53}$ measured urban ambient air PM1.0 on the roof of a building $18 \mathrm{~m}$ above the ground using a UAS-310 in Kaohsiung, Taiwan. The daily average PM1.0 fraction was $52 \pm 21$ (16-108) $\mu \mathrm{g} \mathrm{m}^{-3}$. Another study from Xi'an, an ancient inland city in China by Shen et al. ${ }^{54}$ reported PM1.0 levels on quartz microfiber filters 15 from the roof of a $15 \mathrm{~m}$ high building on the campus of Xi'an Jiaotong University. The average concentration of PM1.0 was 127.3 (27.2 - 73.3) $\mu \mathrm{g} \mathrm{m}^{-3}$.

Compared with the studies reported in western countries, the UFP concentration in Hangzhou is at a medium level (10 428 20147350 particles $\mathrm{cm}^{-3}$ ). However, the PM1.0 levels (30 - $602 \mu \mathrm{g}$ $\mathrm{m}^{-3}$ ) in Hangzhou were higher than those reported in Xi'an, Hong Kong, Kaohsiung and European countries.

\subsection{ARIMA modelling results}

25 The results of ARIMA modelling for UFP and PM1.0 concentration are presented in Table 3.

Table 3 The ARIMA modelling results of UFP and PM1.0 time series data

Estimated parameters (S.E) $p$

UFP (particle $\left.\mathrm{cm}^{-3}\right)^{\mathrm{a}}$

Traffic flow (number of vehicles)

High $(>730)$

Moderate (645 730)

Low $(<645)$

Average driving speed $\left(\mathrm{km} \mathrm{h}^{-1}\right)$

High (>87)

Moderate (80 87)

Low $(<80)$

PM1.0 $\left(\mu \mathrm{g} \mathrm{m}^{-3}\right)^{\mathrm{b}}$

Traffic flow (number of vehicles)

High $(>730)$

Moderate (645 730)

Low $(<645)$

Average driving speed $\left(\mathrm{km} \mathrm{h}^{-1}\right)$

High (>87)

Moderate (80 87)

Low $(<80)$

12681 (3 759)

9774 (3 122)

0.001

Reference

0.002

8529 (3610)

1166 (0558)

0.020

Reference

0.039

$\begin{array}{ll}5.309(2.620) & 0.045 \\ 1.106(2.518) & 0.661\end{array}$

$1.106(2.518)$

0.661

9.638 (3.074)

0.002

6.991 (2.447)

0.005

$30{ }^{\text {a ARIMA }(0} 1$ 1) with constant, stationary $R^{2}=0.726$, p(Ljung-Box Q(18)) $=0.493$.

${ }^{\mathrm{b}}$ ARIMA ( 010 ) with constant, stationary $R^{2}=0.800$, p(Ljung-Box Q(18)) $=0.456$.

35 Results from this study showed that traffic flow was a highly significant predictor of UFP. Compared to UFP levels observed under low traffic flow ( $<645$ vehicles per $10 \mathrm{~min}$ ), there was an increase of 12681 particles $\mathrm{cm}^{-3}(P=0.001)$ in UFP concentration under the high density ( $>730$ vehicles per $10 \mathrm{mins}$ ),

40 after controlling for average driving speed. It is also true that the average driving speed was significantly positively associated with the UFP concentration. Compared to driving in a slow speed $(<80$ $\left.\mathrm{km} \mathrm{h}^{-1}\right)$, driving in a high speed $\left(>87 \mathrm{~km} \mathrm{~h}^{-1}\right)$ was estimated to increase 8529 particles $\mathrm{cm}^{-3}$ in UFP $(p=0.02)$, after controlling 45 the traffic density. The high vehicle density and driving speed also contributed significantly to predicting PM1.0. An increase of $5.309 \mu \mathrm{g} \mathrm{m}^{-3}(p<0.045)$ in PM1.0 was estimated under heavy traffic flow while PM1.0 was increased by $9.638 \mu \mathrm{g} \mathrm{m}^{-3}$ $(p=0.002)$ under the high speed compared to that under the slow 50 speed.

Research focusing on quantifying submicron particle concentrations emitted from vehicles and the impact of traffic flow and driving speed on UFP and PM1.0 on traffic roads is very limited. Few dynamometer studies have reported particle 55 number concentrations under different engine speeds. Holmen and $\mathrm{Qu}^{55}$ did an experiment on speed, acceleration and particle number model analysis during transient operation of compressed natural gas and diesel and found that increase in the speed correlated with increased particle number concentrations. 60 Morawska et al. ${ }^{56}$ tested submicron particles emission from 13 diesel vehicles under different power modes (idle, intermediate and maximum power). They found that in most cases particle number concentrations increased with the increased power output from the engine and emission characteristics did not appear to be ${ }_{65}$ correlated with engine models or vehicle ages. Wang et al. ${ }^{57}$ tested a diesel taxi, a diesel light bus, a gasoline private car and a liquefied petroleum gas (LPG) fuelled taxi with a chassis dynamometer system. The particle number and mass concentrations were measured by SMPS for particles of 15$70700 \mathrm{~nm}$. For all types of vehicles, the particle number and mass concentrations were low at low-idle and low-speed-driving modes, and were high at high-idle and high-speed-driving modes. Concentrations of submicron particles generally increase with the vehicle speed increasing from 10 to $70 \mathrm{~km} \mathrm{~h}^{-1}$. Another 75 dynamometer test by Ristovski et al. reached the same conclusion. $^{58}$ It seems that engine load (which is correlated to speed) is contributed to the particle number and mass concentration. As regards to the vehicle density, majority studies only described the average vehicle numbers in their reports. 80 There are rare studies that used models to quantify its influence on the emission of submicron particles. ${ }^{10,11}$

In this study, we used the strength of ARIMA modeling to provide insights on the temporal distribution of the UFP and PM1.0 data. ARIMA modeling is a well-documented 85 methodology and has been used in some air quality analysis. ${ }^{59-62}$ However, using ARIMA modelling to analyse the average concentration of such tiny air pollutants, like UFP and PM1.0, is not fully researched yet and this study is probably the first example being reported. It is our hope that the findings of this 90 study will serve as a base for future further research to investigate the association between the concentration of UFP/PM1.0 and other factors of interest, such as meteorological factors, and also monitor/forecast real-time concentration of UFP/PM1.0, and hence provide information in policy interventions directed toward 95 improving the local air quality.

The levels of submicron particles observed from this study may reflect the emission factors related to traffic flow/vehicle density, driving speed, and vehicle model proportions (2-3\% diesel fueled vehicles) on the sampling road. Although the daily 100 traffic fleet was relatively heavy on this road, the majority 
vehicles were gasoline fueled. It is well known that diesel vehicles can generate more UFPs than that of gasoline and LPG fuelled vehicles. ${ }^{57,58}$ Thus, it is reasonable that the emission levels of UFPs observed in this study were lower than those 5 observed in the Los Angeles study ${ }^{9}$ and other on-road studies with more heavy duty vehicles. ${ }^{13,19,63}$ In addition, the size range of UFPs needs to be considered when comparing results from different studies as different instruments having different particle size measurement ranges. One limitation of our study is that 10 particle number concentrations smaller than $20 \mathrm{~nm}$ could be underestimated. In regards to the influence of high driving speed on the concentrations of the two parameters of submicron particles, it may indicate that more vehicles are able to drive through the monitoring venue at the same time under high speed.

15 In addition, vehicle speed may affect the local turbulence and inhibit particle coagulation ${ }^{64}$ thus in favour of the generation of smaller particles.

Compared with limited reports on traffic related PM1.0 concentrations, the PM1.0 concentrations observed in this study 20 were higher than other studies such as the Hong Kong study. ${ }^{25}$ As rare studies reported UFP and PM1.0 simultaneously and both of them contribute significantly from vehicle emissions, the similar patterns of influence of vehicle density and driving speed on the concentrations of the two submicron particle parameters indicated 25 that in future traffic related air quality studies, if applicable, measurement on UFP number concentration, PM1.0 and size distribution patterns should all be considered in the study. Whenever possible, data on traffic flow and driving speed should also be collected to justify the results as they are positively 30 correlated with the concentrations of submicron particles in the atmosphere. Moreover, as dilution effect of the sampling venue distance from the road ${ }^{34,63,65,66}$ and sampling methods (mobile vs. fixed sampling) may affect the concentrations of submicron particles, these factors need to be considered in interpreting the 35 results from monitoring.

Some other factors such as the influence of temperature and wind speed on submicron particles need to be studied ${ }^{10-12,47,63}$ as these factors may have confounding effects on the behavior of these tiny particles in the atmosphere. Although the original key 40 purpose of this paper is to investigate the effect of traffic flow and driving speed on the UFP and PM1.0 concentrations, additional ARIMA models were rerun with temperature and wind speed to adjust their confounding association with UFP and PM1.0 concentration. Not surprisingly, when the temperature and 45 wind speed were introduced into the ARIMA model, the new results were similar to the results shown in Table 3 (the new modeling results are not provided). These additional results further suggest that traffic flow and average driving speed were significant positively associated with UFP and PM1.0, even after 50 controlling for the temperature and wind speed.

\section{Conclusions}

In this paper we have applied the ARIMA model to analyse the concentration of submicron particles, with an aim to detect the 55 influence of the traffic relevant factors on the two indicators of submicron particles. We trust that the ARIMA model has provided an acceptable description of the correlation structures of the two concentrations being investigated and also built up a reasonable relationship between the two indicators and the traffic
60 relevant factors, even controlling for some meteorological confounders.

This preliminary investigation provides background information on mass concentrations of particles equal and less than $1.0 \mu \mathrm{g} \mathrm{m}^{-3}$ and UFP number concentrations on a busy traffic 65 road in the city centre of Hangzhou, China. Concentrations of submicron particles can be affected by vehicle density, driving speed and possibly, vehicle types. It may be useful in future studies to look at the influence of acceleration/deceleration of vehicles on the emission patterns of submicron particles.

70 Because of the small size and large surface area of UFPs (nanoparticles), these tiny air pollutants are able to gain entry more deeply into the respiratory system. Thus, further larger scale studies are necessary to ascertain air quality correlated with ultrafine particles and PM1.0 from vehicle emissions and the 75 impact and underlying mechanism of vehicle factors and other environmental factors on the air quality. Future investigation in the causal relationship between UFP and PM1.0 exposure and adverse effects on community public health is also a demanding area that needs more efforts.

80

\section{Acknowledgements}

The authors would like to thank staff at Hangzhou Traffic Administration and Control Centre and The Vehicle Licensing Centre for their kind help in providing relative data for this study 85 and Professor Colin Binns for his review and comments on the paper.

\section{References}

1. National Bureau of Statistics of China, National Bureau of Statistics $90 \quad$ of China, Beijing, Editon edn., 2010.

2. EPA, Glossary of Climate Change Terms, $\quad$ http://epa.gov/climatechange/glossary.html\#P, Accessed 26 Dec 2009, 2009.

3. M. Fang, C. K. Chan and X. H. Yao, Atmospheric Environment, $95 \quad$ 2009, 43, 79-86.

4. L. Y. He, M. Hu, Y. H. Zhang, X. F. Huang and T. T. Yao, Environ Sci Technol, 2008, 42, 4461-4466.

5. F. K. Duan, K. B. He, Y. L. Ma, F. M. Yang, X. C. Yu, S. H. Cadle, T. Chan and P. A. Mulawa, Sci Total Environ, 2006, 355, 264275.

6. F. Yang, K. He, Y. Ma, Q. Zhang, S. H. Cadle, T. Chan and P. A. Mulawa, Journal of the Air \& Waste Management Association (1995), 2005, 55, 984-992.

7. G. Wang, L. Huang, S. Gao and L. Wang, Chemosphere, 2002, 48, 105 689-695.

8. C. Seigneur, Journal of the Air \& Waste Management Association (1995), 2009, 59, 3-17.

9. D. Westerdahl, S. Fruin, T. Sax, P. M. Fine and C. Sioutas, Atmospheric Environment, 2005, 39, 3597-3610.

110 10. S. Weichenthal, A. Dufresne, C. Infante-Rivard and L. Joseph, $J$ Expo Sci Environ Epidemiol, 2008, 18, 551-563.

11. S. Kaur and M. J. Nieuwenhuijsen, Environ Sci Technol, 2009, 43, 4737-4743. 
12. C. A. Noble, S. Mukerjee, M. Gonzales, C. E. Rodes, P. A. Lawless, S. Natarajan, E. A. Myers, G. A. Norris, L. Smith, H. Ozkaynak and L. M. Neas, Atmospheric Environment, 2003, 37, 827-840.

5 13. Y. G. Wang, Y. F. Zhu, R. Salinas, D. Ramirez, S. Karnae and K. John, J Air Waste Manage, 2008, 58, 1449-1457.

14. U. Makkonen, H. Hellen, P. Anttila and M. Ferm, Science of the Total Environment, 2010, 408, 644-651.

15. A. Charron and R. M. Harrison, Atmospheric Environment, 2003, 37, 10 4109-4119.

16. P. Molnar, S. Janhall and M. Hallquist, Atmospheric Environment, 2002, 36, 4115-4123.

17. L. Laakso, T. Hussein, P. Aarnio, M. Komppula, V. Hiltunen, Y. Viisanen and M. Kulmala, Atmospheric Environment, 2003,

15 37, 2629-2641.

18. G. C. Fang, Y. S. Wu, S. Y. Chang, J. Y. Rau, S. H. Huang and C. K. Lin, Toxicol Ind Health, 2006, 22, 27-37.

19. G. S. W. Hagler, R. W. Baldauf, E. D. Thoma, T. R. Long, R. F. Snow, J. S. Kinsey, L. Oudejans and B. K. Gullett, 20 Atmospheric Environment, 2009, 43, 1229-1234.

20. M. J. Kleeman, S. G. Riddle, M. A. Robert, C. A. Jakober, P. M. Fine, M. D. Hays, J. J. Schauer and M. P. Hannigan, Environ Sci Technol, 2009, 43, 272-279.

21. C. C. Lin, S. J. Chen, K. L. Huang, W. J. Lee, W. Y. Lin, J. H. Tsai

25 and H. C. Chaung, Environ Sci Technol, 2008, 42, 4229-4235.

22. U. Matson, Sci Total Environ, 2005, 343, 169-176.

23. Z. Ning, M. D. Geller, K. F. Moore, R. Sheesley, J. J. Schauer and C. Sioutas, Environ Sci Technol, 2007, 41, 6000-6006.

24. L. Morawska, D. U. Keogh, S. B. Thomas and K. Mengersen,

$30 \quad$ Atmospheric Environment, 2008, 42, 1617-1628.

25. S. C. Lee, Y. Cheng, K. F. Ho, J. J. Cao, P. K. K. Louie, J. C. Chow and J. G. Watson, Aerosol Science and Technology, 2006, 40, 157-165.

26. F. Alessandrini, I. Beck-Speier, D. Krappmann, I. Weichenmeier, S.

35 Takenaka, E. Karg, B. Kloo, H. Schulz, T. Jakob, M. Mempel and H. Behrendt, Am J Respir Crit Care Med, 2009, 179, 984991.

27. A. Valavanidis, K. Fiotakis and T. Vlachogianni, J Environ Sci Health C Environ Carcinog Ecotoxicol Rev, 2008, 26, 339-

40 362.

28. W. Kreyling, M. Semmler-Behnke and W. Möller, Journal of Nanoparticle Research, 2006, 8, 543-562.

29. K. J. Chuang, C. C. Chan, G. M. Shiao and T. C. Su, Journal of occupational and environmental medicine / American College

45 of Occupational and Environmental Medicine, 2005, 47, 10931098.

30. J. A. Araujo, B. Barajas, M. Kleinman, X. Wang, B. J. Bennett, K. W. Gong, M. Navab, J. Harkema, C. Sioutas, A. J. Lusis and A. E. Nel, Circ Res, 2008, 102, 589-596.

50 31. R. J. Delfino, C. Sioutas and S. Malik, Environ Health Perspect, 2005, 113, 934-946.

32. L. Morawska, H. Wang, Z. Ristovski, E. R. Jayaratne, G. Johnson, H. C. Cheung, X. Ling and C. He, J Environ Monitor, 2009, 11, 1758-1773.
55 33. L. A. Wallace, A. J. Wheeler, J. Kearney, K. Van Ryswyk, H. You, R. H. Kulka, P. E. Rasmussen, J. R. Brook and X. Xu, J Expo Sci Environ Epidemiol, 2010.

34. B. Beckerman, M. Jerrett, J. R. Brook, D. K. Verma, M. A. Arain and M. M. Finkelstein, Atmospheric Environment, 2008, 42, 275$60 \quad 290$

35. J. L. Abraham, G. Siwinski and A. Hunt, The Annals of occupational hygiene, 2002, 46, 406-411.

36. L. A. Wallace, A. J. Wheeler, J. Kearney, K. Van Ryswyk, H. Y. You, R. H. Kulka, P. E. Rasmussen, J. R. Brook and X. H. Xu, J Expo Sci Env Epid, 2011, 21, 49-64.

65

37. S. Kingham, M. Durand, T. Aberkane, J. Harrison, J. G. Wilson and M. Epton, Atmospheric Environment, 2006, 40, 338-347.

38. J. Y. Kim, S. R. Magari, R. F. Herrick, T. J. Smith and D. C. Christiani, Journal of occupational and environmental hygiene, 2004, 1, 707-715.

39. U. Matson, L. E. Ekberg and A. Afshari, Aerosol Science and Technology, 2004, 38, 487-495.

40. M. Vana, E. Tamm and M. Viil, Atmospheric Environment, 1999, 33, 4615-4628.

75 41. T. Slini, K. Karatzas and N. Moussiopoulos, Science of the Total Environment, 2002, 288, 227-237.

42. W. W. S. Wei, Time series analysis: univariate and multivariate methods, 2nd edn., Addison Wesley Pub, 2006.

43. Hangzhou Bureau of Statistics, Hangzhou Statistical Yearbook 80 2009, http://www.hzstats.gov.cn/web/more2.aspx?id=EuvfD1 $75 \mathrm{mjE}=$ \&name=vdpsN636PcaolV18yOEw4A==, Accessed 13 April 2011, 2011.

44. D. B. Kittelson, Journal of Aerosol Science, 1998, 29, 575-588.

45. Z. D. Ristovski, E. R. Jayaratne, M. Lim, G. A. Ayoko and L. 85 Morawska, Environmental Science \& Technology, 2006, 40, 1314-1320.

46. S. J. Harris and M. M. Maricq, Journal of Aerosol Science, 2001, 32, 749-764.

47. L. Pirjola, H. Parviainen, T. Hussein, A. Valli, K. Hameri, P. Aaalto, 90 A. Virtanen, J. Keskinen, T. A. Pakkanen, T. Makela and R. E. Hillamo, Atmospheric Environment, 2004, 38, 3625-3635.

48. D. B. Kittelson, W. F. Watts, J. P. Johnson, M. L. Remerowki, E. E. Ische, G. Oberdorster, R. M. Gelein, A. Elder, P. K. Hopke, E. Kim, W. Zhao, L. Zhou and C. H. Jeong, Inhal Toxicol, 2004, 16 Suppl 1, 31-39.

49. D. L. Yue, M. Hu, Z. J. Wu, S. Guo, M. T. Wen, A. Nowak, B. Wehner, A. Wiedensohler, N. Takegawa, Y. Kondo, X. S. Wang, Y. P. Li, L. M. Zeng and Y. H. Zhang, Atmospheric Chemistry and Physics, 2010, 10, 9431-9439.

100 50. N. Perez, J. Pey, M. Cusack, C. Reche, X. Querol, A. Alastuey and M. Viana, Aerosol Science and Technology, 2010, 44, 487499.

51. S. Rodriguez, E. Cuevas, Y. Gonzalez, R. Ramos, P. M. Romero, N. Perez, X. Querol and A. Alastuey, Atmospheric Environment, $105 \quad$ 2008, 42, 6523-6534.

52. V. Ariola, A. D'Alessandro, F. Lucarelli, G. Marcazzan, F. Mazzei, S. Nava, I. Garcia-Orellana, P. Prati, G. Valli, R. Vecchi and A. Zucchiatti, Chemosphere, 2006, 62, 226-232.

53. J. J. Lin and L. C. Lee, Atmospheric Environment, 2004, 38, 469-475. 
54. Z. X. Shen, J. J. Cao, R. Arimoto, Y. M. Han, C. S. Zhu, J. Tian and S. X. Liu, Aerosol Science and Technology, 2010, 44, 461472.

55. B. A. Holmen and Y. Qu, Environ Sci Technol, 2004, 38, 2413-2423.

5 56. L. Morawska, N. D. Bofinger, L. Kocis and A. Nwankwoala, Environmental Science \& Technology, 1998, 32, 2033-2042.

57. J. S. Wang, T. L. Chan, Z. Ning, C. S. Cheung and Z. Huang, Huan jing ke xue= Huanjing kexue / [bian ji, Zhongguo ke xue yuan huan jing ke xue wei yuan hui "Huan jing ke xue" bian ji wei

10 yuan hui, 2006, 27, 2382-2385.

58. Z. D. Ristovski, E. R. Jayaratne, L. Morawska, G. A. Ayoko and M. Lim, Sci Total Environ, 2005, 345, 93-98.

59. U. Kumar and V. K. Jain, Stoch Env Res Risk A, 2010, 24, 751-760.

60. L. A. Diaz-Robles, J. C. Ortega, J. S. Fu, G. D. Reed, J. C. Chow, J.

15 G. Watson and J. A. Moncada-Herrera, Atmospheric Environment, 2008, 42, 8331-8340.

61. K. Kumar, A. K. Yadav, M. P. Singh, H. Hassan and V. K. Jain, J Air Waste Manage, 2004, 54, 809-814.

62. V. R. Prybutok, J. S. Yi and D. Mitchell, Eur J Oper Res, 2000, 122,

20 31-40.

63. V. M. Kerminen, T. A. Pakkanen, T. Makela, R. E. Hillamo, M. Sillanpaa, T. Ronkko, A. Virtanen, J. Keskinen, L. Pirjola, T. Hussein and K. Hameri, Atmospheric Environment, 2007, 41, 1759-1767.

25 64. P. Jiang, D. O. Lignell, K. E. Kelly, J. S. Lighty, A. F. Sarofim and C. J. Montgomery, Journal of the Air \& Waste Management Association (1995), 2005, 55, 437-445.

65. T. Kuhn, S. Biswas and C. Sioutas, Atmospheric Environment, 2005, 39, 7154-7166.

30 66. Y. F. Zhu, W. C. Hinds, S. Kim, S. Shen and C. Sioutas, Atmospheric Environment, 2002, 36, 4323-4335. 